\title{
Duodenal-Type Follicular Lymphoma
}

National Cancer Institute

\section{Source}

National Cancer Institute. Duodenal-Type Follicular Lymphoma. NCI Thesaurus. Code C138185.

A localized low-grade follicular lymphoma within the gastrointestinal tract, which is distinct from other gastrointestinal tract follicular lymphomas. It has features that overlap with in situ follicular neoplasia as well as some features resembling an extranodal marg inal zone lymphoma of mucosa-associated lymphoid tissue. The prognosis is excellent. 